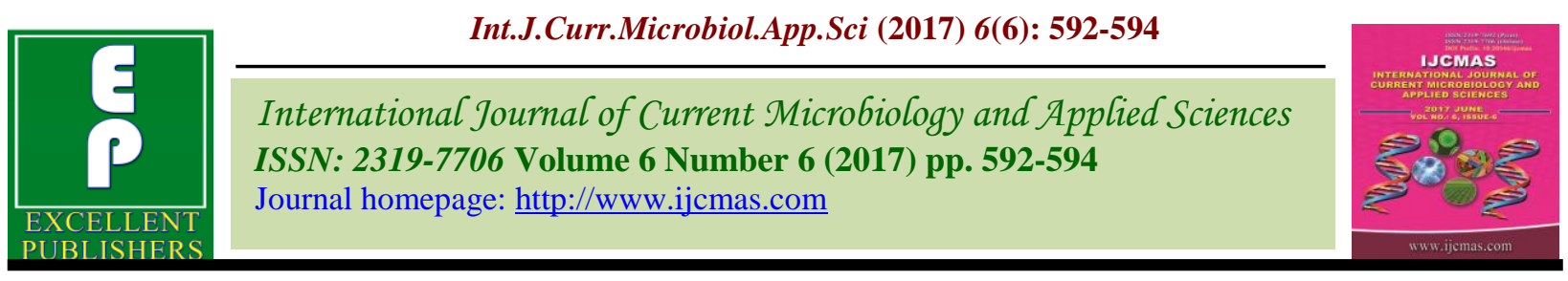

Review Article

https://doi.org/10.20546/ijcmas.2017.606.069

\title{
A Holistic Approach for Mine Spoil Restoration
}

\author{
Preeti Singh, Seema ${ }^{1 *}$ and Hansa Lakhran ${ }^{2}$ \\ ${ }^{1}$ Department of Soil Science and Agricultural Chemistry, \\ Institute of Agricultural Sciences, Banaras Hindu University, Varanasi, India \\ ${ }^{2}$ Department of Agronomy, S. K. N. Agriculture University, Jobner, Jaipur, \\ Rajasthan-303329, India \\ *Corresponding author
}

\section{A B S T R A C T}

\section{Keywords}

Overburden,

Mining,

Agriculture,

Reclaimation and

Climate change.

Article Info

Accepted:

04 May 2017

Available Online:

10 June 2017
Energy is needed for economic growth and more than $70 \%$ of the energy generation capacity in India is by using coal. The production of coal was 430.83 Mt out of which opencast contributed to around 373 Mt in 2006 with an estimated overburden removal of 600 million $\mathrm{m}^{3}$. In India, opencast mining is most prominent method of coal excavation. However, each year hundreds of acres of pristine forest and productive agricultural land are brought in the gambit of open cast coal mining. Moreover, open cast mining leaves behind a lot of over burden which is an environmental problem. Faced with a burgeoning population, agriculture in India must bring under its gambit the non-conventional or nontraditional area, to feed the teeming millions. Reclaimed coal mine areas could be the non-traditional areas. A holistic restoration approach can also address the challenges of global climate change by sequestering large amount of atmospheric carbon dioxide and qualify for the carbon credit earning under the Kyoto Protocol.

\section{Introduction}

Plantations are useful for enhancing the productivity of degraded landscape under a variety of circumstances; it accelerate the soil-forming processes, control erosion, build up organic matter, develop microbial communities, initiate nutrient cycling, decreases air and water pollution, reduces geo-environmental disasters, maintain biodiversity and enhance overall aesthetics of the area, however they are inadequate minespoil restoration tools in isolation. It is argued that to restore mine overburden, a broader vision that incorporates holistic science is called for. Indeed, we shall have to use a feasible way to address the imperilled nature-society interactions as well as to construct a self-sustaining functional ecosystem capable of supporting biodiversity, performing ecosystem functioning and providing ecosystem services to society (Pandey, 2002; Kates et al., 2001).

\section{Approaches}

In addition to amelioration of local environment, a holistic restoration approach can also address the challenges of global 
climate change by sequestering large amount of atmospheric carbon dioxide and qualify for the carbon credit earning under the Kyoto Protocol (Pandey, 2002; Gupta and Rao, 1994; Akala and Lal, 2000). I wish to suggest that holistic strategy for restoration of minespoil must essentially include the following: (i) Policy measures and incentive mechanism to store fertile top-soil layer for use in post mining restoration operation, (ii) protection to adjacent refugee, remnant vegetation and ancient trees, (iii) attracting seed dispersers, (iv) rainwater harvesting, (v) assisted soil remediation through addition of pond-bed silt and sediment as well as earthworm, (vi) assistance to available persistent rootstock, if any, (vii) direct seeding, (viii) vegetative cutting and (ix) plantations, such as proposed by Singh et al., (2002) as a last option if need be, should be resorted to only in sequential combination with strategies suggested here. Design and enforcement of mining and restoration policy must accept the role of incentives to retrieve and store topsoil before starting the mining operations. Throughout the mining operations, protection to adjacent vegetation that is likely to serve as seed source in the vicinity is required.

Catalyzing natural regeneration of native forest species originating from remnant forests and ancient trees in the vicinity is a useful method in combination with direct seeding and increases likelihood of restoration success. Remnant vegetation also supports a variety of fauna that help in seed dispersal in adjacent areas. Such a primary succession in post-mining landscapes has been found to be useful.

Rainwater harvesting is a crucial step for ecological restoration of mine-spoils (Akala and Lal, 2000 and Pandey, 2001). For example, rehabilitation success to revegetate mine-spoils in arid regions in India was achieved using a combination of rainwater harvesting, soil amendments and plant establishment methods using trees, shrubs and grasses. Such an approach is also socially useful to enhance productivity and availability of products to people (Sharma et al., 2001). Addition of organic wastes has been found to increase $\mathrm{N}$ fertility at a surface coal mine reclamation site, which ultimately stimulated microbial activity and improved the chemical and physical properties of the reclaimed soil (Coyne et al., 1998).

Silt of the traditional rainwater harvesting systems, called ponds and tanks, is the most effective indigenous soil amendment practice in India. Pond silt is not only mineral-rich, but also a seed bank for a variety of grasses, herbs, shrubs and trees. Restoration of a variety of wastelands, including mine overburden by direct seeding, planting of large vegetative cuttings, and wherever possible, assistance to persistent root-stock has provided effective results in Rajasthan (Pandey, 1996). Although persistent rootstock recovery will not be a chief strategy as spoil heaps may be too high to overcome, nevertheless, peripheral dump areas have been reclaimed by assistance to root-stock through a combination of rainwater harvesting. Direct seeding of native species has proved a most useful and cost-effective restoration method (Pandey, 1996, 1998).

Seed mixture for direct seeding must be carefully selected based on physical and chemical properties of mine-spoil as well as ecological, economic and social criteria. A useful approach is to include framework species across taxa, herbs, shrubs and trees, early and late successional species, as well as a select few keystone species to accelerate the restoration of a functional ecosystem. Direct sowing also provides a large base for choice of species. Since it is not necessary to raise the seedling in the nursery, a large number of species can be tried out, compared to planting. 
Production of seedlings in the forest nursery requires large inputs in terms of time and money. This can be avoided by opting for direct sowing. Direct sowing is also advantageous as it is comparatively easier to maintain the species mix than in a plantation. It can be combined with planting, natural regeneration or both. Direct sowing helps in enhancing biodiversity per unit area. Direct sowing requires a simple technique for rainwater harvesting in combination with minimal soil work. Thus, ecologically sound multi-tier vegetation can be effectively developed (Pandey, 1998).

In conclusion, I would reiterate that we would also need to draw on the cultural resources such as local knowledge and skills to help address the challenge of mine-spoil restoration. A broader vision alone can address the productivity enhancement of wastelands such as mine-spoil, and can contribute to overall approach for ecological, economic and social sustainability in India. A holistic approach suggested here is a step in that direction.

\section{References}

Akala, V. A. and Lal, R., Land Degrad. Dev., (2000), Potential of land reclamation for soil organic carbon sequestration in Ohio. 11, 289-297.

Coyne, M. S., Zhai, Q., MacKown, C. T. and Barnhisel, R. I., Gross nitrogen transformation rates in soil at a surface coal mine site reclaimed for prime farmland use. Soil Biol. Biochem., (1998), 30, 1099 -1106.
Gupta, R. K. and Rao, D. L. N., ibid. (1994), Potential of wastelands for sequestering carbon by reforestation. Current Science, 66, 378-380.

Kates, R. W. et al., Science, (2001), Environment and development. Sustainability science. 292, 641-642.

Pandey, D. N., Beyond Vanishing Woods: Participatory Survival Options for Wildlife, Forests and People, CSD \& Himanshu, New Delhi, (1996), p. 222.

Pandey, D. N., Beyond Vanishing Woods: Participatory Survival Options for Wildlife, Forests and People, CSD \& Himanshu, New Delhi, (1996), p. 222.

Pandey, D. N., Multifunctional agroforestry systems in India. Conserv. Ecol., (2002), 6, r13.

Pandey, D. N., Global climate change and carbon management in multifunctional forests. Curr. Sci., (2002), 83, 593-602.

Pandey, D. N., Ethnoforestry: Local Knowledge for Sustainable Forestry and Livelihood Security, Himanshu/AFN, New Delhi, (1998)

Pandey, D. N., Science, (2001), A bountiful harvest of rainwater. Science, 293 (5536), 1763.

Sharma, K. D., Kumar, S. and Gough, L. P., Rehabilitation of gypsum-mined lands in the Indian Desert. Arid Land Res. Manage, (2001), 15, 61-76.

Singh, A. N., Raghubanshi, A. S. and Singh, Plantations as a tool for mine spoil restoration. J. S., Curr. Sci., (2002), 82, 1436-1441.

\section{How to cite this article:}

Preeti Singh, Seema and Hansa Lakhran. 2017. A Holistic Approach for Mine Spoil Restoration. Int.J.Curr.Microbiol.App.Sci. 6(6): 592-594. doi: https://doi.org/10.20546/ijcmas.2017.606.069 